\title{
Universal reverse-transcriptase real-time PCR for infectious hematopoietic necrosis virus (IHNV)
}

\author{
Maureen K. Purcell ${ }^{1, *}$, Rachel L. Thompson ${ }^{1}$, Kyle A. Garver ${ }^{2}$, Laura M. Hawley ${ }^{2}$, \\ William N. Batts ${ }^{1}$, Laura Sprague ${ }^{3}$, Corie Sampson ${ }^{3}$, James R. Winton ${ }^{1}$ \\ ${ }^{1}$ Western Fisheries Research Center, US Geological Survey, 6505 NE 65th St., Seattle, Washington 98115, USA \\ ${ }^{2}$ Pacific Biological Station, Fisheries and Oceans Canada, Aquatic Animal Health, \\ 3190 Hammond Bay Road, Nanaimo, British Columbia V9T 6N7, Canada \\ ${ }^{3}$ Idaho Fish Health Center, US Fish and Wildlife Service, Orofino, Idaho 83544, USA
}

\begin{abstract}
Infectious hematopoietic necrosis virus (IHNV) is an acute pathogen of salmonid fishes in North America, Europe and Asia and is reportable to the World Organization for Animal Health (OIE). Phylogenetic analysis has identified 5 major virus genogroups of IHNV worldwide, designated $\mathrm{U}, \mathrm{M}, \mathrm{L}, \mathrm{E}$ and $\mathrm{J}_{\text {; }}$ multiple subtypes also exist within those genogroups. Here, we report the development and validation of a universal IHNV reverse-transcriptase real-time PCR (RT-rPCR) assay targeting the IHNV nucleocapsid (N) gene. Properties of diagnostic sensitivity (DSe) and specificity (DSp) were defined using laboratory-challenged steelhead trout Oncorhynchus mykiss, and the new assay was compared to the OIE-accepted conventional PCR test and virus isolation in cell culture. The IHNV N gene RT-rPCR had $100 \%$ DSp and DSe and a higher estimated diagnostic odds ratio (DOR) than virus culture or conventional PCR. The RT-rPCR assay was highly repeatable within a laboratory and highly reproducible between laboratories. Field testing of the assay was conducted on a random sample of juvenile steelhead collected from a hatchery raceway experiencing an IHN epizootic. The RT-rPCR detected a greater number of positive samples than cell culture and there was $40 \%$ agreement between the 2 tests. Overall, the RT-rPCR assay was highly sensitive, specific, repeatable and reproducible and is suitable for use in a diagnostic setting.
\end{abstract}

KEY WORDS: Infectious hematopoietic necrosis virus $\cdot$ HNV $\cdot$ Real-time PCR $\cdot$ Diagnostic validation $\cdot$ Field validation $\cdot$ Steelhead trout $\cdot$ Reproducibility $\cdot$ Genogroup

\section{INTRODUCTION}

Infectious hematopoietic necrosis virus (IHNV) is a pathogen that causes acute disease in wild and cultured salmonid fishes (Bootland \& Leong 2009). Common clinical signs of infectious hematopoietic necrosis (IHN) are darkening, lethargy, exophthalmia, pale gills, distended abdomen and petechial hemorrhaging; however, mortality can occur in the absence of clinical signs (Amend et al. 1969, Wolf 1988). IHN is 1 of only 9 finfish diseases reportable to the World Organization for Animal Health (OIE 2012). Phyloge- netic analysis has identified 5 major genogroups of IHNV worldwide, designated U, M, L, E and J (Kurath 2012). The U, M, and L genogroups are all present in Western North America and correspond to the upper, middle and lower portions of the IHNV geographical range (Kurath et al. 2003). In Europe, M genogroup IHNV strains were initially introduced, but the viral lineage has since evolved in rainbow trout farms to represent a new, European (E) genogroup (Enzmann et al. 2005, 2010, Johansson et al. 2009, Kurath 2012). Isolates from salmonids in the Russian Far East and Asia typically cluster within the 
U genogroup, but a unique genogroup $(\mathrm{J})$ is present in Japan and Korea (Nishizawa et al. 2006, Kim et al. 2007, Rudakova et al. 2007). IHNV taxonomically groups within the family Rhabdoviridae and genus Novirhabdovirus; the genus also includes the species Viral hemorrhagic septicemia virus (VHSV), Hirame rhabdovirus (HIRRV) and Snakehead rhabdovirus (SHRV) (Kurath 2012).

The standard detection method for IHNV is isolation of the virus in cell culture, followed by identification - typically with a molecular-based test such as PCR (AFS 2012). Culture is highly sensitive, detects only viable virus and allows isolation of all genogroups in susceptible cell lines (Batts \& Winton 1989). Although culture remains the standard for IHNV detection, the 7 to $21 \mathrm{~d}$ incubation period required can limit its usefulness for certain applications. Reverse-transcriptase conventional polymerase chain reaction (RT-cPCR) assays targeting viral genes have been developed for IHNV screening and confirmation, and can expedite diagnosis relative to cell culture (Arakawa et al. 1990, Winton \& Einer-Jensen 2002). More recently, diagnostic assays based on real-time PCR technology have become popular for pathogen surveillance because real-time PCR assays which utilize a hydrolysis probe yield rapid results, are typically highly sensitive and specific, may provide an estimate of viral load, and lend themselves to high sample through-put (Purcell et al. 2011). Several reverse transcriptase quantitative or real-time PCR (RT-qPCR or RT-rPCR) assays for IHNV have been reported previously (Overturf et al. 2001, Purcell et al. 2006, Dhar et al. 2008, Liu et al. 2008).

IHNV possesses a single-stranded, negative-sense RNA genome of approximately $11 \mathrm{~kb}$ in length (Morzunov et al. 1995). The genome encodes 6 mRNA molecules that are translated into 6 proteins: the nucleocapsid protein $(\mathrm{N})$, phosphoprotein $(\mathrm{P})$, matrix protein $(\mathrm{M})$, glycoprotein $(\mathrm{G})$, nonvirion protein $(\mathrm{NV})$, and polymerase protein (L) (Kurath \& Leong 1985, Kurath et al. 1985). The most commonly used molecular test for confirmation of IHNV from cell culture is an RT-cPCR assay that targets the central region of the G protein gene (AFS 2012, OIE 2012). This assay has the added advantage in that sequencing of the RT-cPCR product has been used widely for genetic typing of IHNV isolates and determination of viral genogroups (Kurath et al. 2003).

The ideal target for a PCR-based diagnostic test is a gene that has been well-characterized such as the IHNV G gene which is characterized for strain typing. However, the higher nucleotide diversity within the G gene may increase the likelihood that emerg- ing strains may not be detected due to nucleotide mismatches present in the PCR primer or probe binding sites. Additionally, the G protein is the only protein capable of eliciting protective immunity and is the basis of a highly efficacious and commercially licensed IHN DNA vaccine (Engelking \& Leong 1989, Anderson et al. 1996, Salonius et al. 2007). Thus, a PCR-based test that targets the G gene may not be suitable in vaccinated fish populations. Due to similar concerns, the viral $\mathrm{N}$ gene was targeted for development and validation of a universal reverse transcriptase quantitative PCR (RT-qPCR) assay to detect the related VHS virus (Garver et al. 2011). Furthermore, targeting the $\mathrm{N}$ gene may result in a more sensitive PCR assay because this gene has the highest rate of transcription relative to the other rhabdoviral genes (Rose \& Schubert 1987, Arakawa et al. 1990).

The goal of this study was to develop and validate a universal IHNV RT-rPCR assay targeting the IHNV $\mathrm{N}$ gene. The term 'real-time PCR' was used to describe the assay because results from the test were interpreted as positive or negative rather than quantitatively. To be an effective diagnostic tool, the universal IHNV RT-rPCR assay must be able to detect all known IHNV genotypes (pan-specific) but not related viral species, be sensitive enough to reliably detect viral loads typically found in infected fish, be robust across laboratories, and provide advantages over other diagnostic methods for IHNV. A review of the previously published IHNV RT-rPCR assays found that none of these assays were well suited for use as a pan-specific IHNV assay due to known sequence variation in the primer and/or probe sites, or because they targeted variable regions of the $\mathrm{G}$ or $\mathrm{N}$ gene. Thus, we developed a novel assay and defined properties of analytical and diagnostic sensitivity and specificity. The IHNV RT-rPCR assay reported here is fit for diagnostic testing and provides a simple, fast, sensitive and specific tool that produces reliable results equal to or better than cell culture and/or the currently recommended conventional PCR method.

\section{MATERIALS AND METHODS}

\section{Virus isolates}

IHNV was propagated in epithelioma papulosum cyprini (EPC) cells (Fijan et al. 1983, Winton et al. 2010) using minimum essential medium (Gibco) supplemented with $10 \%$ fetal bovine serum (HyClone, Thermo Fisher Scientific) (Batts \& Winton 1989). 
Virus was quantified by plaque assay on polyethylene glycol-treated EPC cells as previously described (Batts \& Winton 1989).

\section{RNA extraction}

Total RNA was extracted from homogenized tissue or cell culture supernatant using the RNeasy® Mini Kit or the QIAamp® Viral RNA Mini Kit (Qiagen), respectively, following manufacturer's instructions. Tissue samples (approximately 25 to $30 \mathrm{mg}$ ) preserved in RNAlater (Ambion) were homogenized with a Fast-Prep®-24 bead beater (MP Biomedical) for $20 \mathrm{sec}$ using $1.0 \mathrm{~mm}$ zirconia/silica beads (BioSpec Products). Total RNA was eluted in $60 \mu \mathrm{l}$ of nuclease-free water and stored at $-80^{\circ} \mathrm{C}$ until used. Total RNA was quantified using the Nanodrop ND1000 (Thermo Scientific).

\section{Universal primers and probe design}

A conserved region within the IHNV $\mathrm{N}$ gene was identified through sequence alignment of all available IHNV full and partial N-gene sequences in GenBank (FJ265710-FJ265715, AY442507- AY44 2518, HM461966, AY737257, AB231658, AY673683, AY438975, U50402, and HM099906) and in-house sequences. Primers and a fluorescent $6-\mathrm{FAM}^{\mathrm{TM}}$ labeled TaqMan ${ }^{\circledR}$ minor groove binding probe (Life
Technologies) were designed using Primer Express Software V.3.0 (Life Technologies). Primers and probes were named for the 5' base nucleotide number that corresponded to the complete genome sequence available for the American Type Culture Collection (ATCC) reference IHNV strain (ATCC VR-1392; GenBank NC_001652). Primer and probe sequences are shown in Fig. 1B.

\section{Artificial positive control (APC) plasmid and probe}

An artificial positive control (APC) plasmid was designed for use as an exogenous control based on the universal construct reported by Snow et al. (2009), with the substitution of kanamycin as the selective antibiotic. Briefly, an artificial construct was synthesized by Integrated DNA Technologies that contained target sequences for the IHNV primers and probe plus the addition of an artificial probe binding site (Fig. 1) and cloned into the pIDT Smart vector (Integrated DNA Technologies). A probe that would bind to the artificial site was synthesized and labeled with a fluorescent VIC@ reporter dye (Life Technologies). This probe was added to the RT-rPCR reaction mixture to detect any contamination from the plasmid DNA. The plasmid DNA was used as a positive control in separate reaction wells and to generate an IHNV N-gene standard curve. The APC plasmid was used to determine absolute $\mathrm{N}$ gene copy number based on a plasmid molecular weight of $1.3 \times$

\begin{tabular}{|c|c|}
\hline \multicolumn{2}{|l|}{ (A) } \\
\hline \multicolumn{2}{|c|}{ CCATGGTAATACGACTCACTATAGGGCGACCCGCCAGAGCCAAGGCACTGTGCG CCATGAG } \\
\hline \multicolumn{2}{|c|}{ ACTGAGCGGGACA GGAATGaccgtctagcatccagt ACAATGGTGGGGCTGTTCAACCAAGCCGCA } \\
\hline \multicolumn{2}{|c|}{ AAGAA CCTGGGCGCCTTCTATAGTGTCACCTAAATACTAGT } \\
\hline \multicolumn{2}{|l|}{ (B) } \\
\hline Key & Sequence (5'-3') \\
\hline Ncol restriction enzyme site & CCATGG \\
\hline Spel restriction enzyme site & ACTAGT \\
\hline T7 RNA polymerase promoter sequence & TAATACGACTCACTATAGGGCGA \\
\hline SP6 RNA polymerase promoter sequence & TTCTATAGTGTCACCTAAAT \\
\hline Arbitrary tag sequence probe target site & VIC-accgtctagcatccagt-NFQ/MGB \\
\hline IHNV N 796F & AGAGCCAAGGCACTGTGCG \\
\hline IHNV N 818MGB & 6FAM-TGAGACTGAGCGGGACA-NFQ/MGB \\
\hline IHNV N 875R & TTCTTTGCGGCTTGGTTGA \\
\hline
\end{tabular}

Fig. 1. Sequence structure of the artificial positive control (APC) plasmid for infectious hematopoietic necrosis virus reverse transcriptase real-time PCR (RT-rPCR) targeting the nucleocapsid N gene. (A) Plasmid sequence insert, (B) sequence key. APC construct was based on the design reported by Snow et al. (2009) 
$10^{6} \mathrm{~g} \mathrm{~mol}^{-1}$; copy number calculations are as previously described (Purcell et al. 2006). The plasmid DNA was diluted to a standard copies per $\mu \mathrm{l}$, and serially diluted in 10-fold increments down to 1 copy per $\mu$ l. All plasmid DNA was stored as aliquots at $-80^{\circ} \mathrm{C}$ until used.

The artificial construct was supplied by the vendor as plasmid DNA and the plasmid was transformed upon receipt into TOP-10 One-Shot Cells (Invitrogen) following the manufacturer's recommendations. Plasmid DNA was purified using the QIAquick Miniprep Spin Kit (Qiagen) according to the manufacturer's instructions and quantified using the Nanodrop ND-1000 (Thermo Fisher Scientific). Plasmid DNA was linearized with the NcoI restriction enzyme, purified using the QIAquick PCR Purification Kit (Qiagen), and used as template for synthesis of in vitro RNA transcripts using Sp6 RNA polymerase following reaction conditions previously described (Purcell et al. 2006). The in vitro RNA transcripts were stored in single-use aliquots at $-80^{\circ} \mathrm{C}$ and diluted in 10-fold increments for standard curve tests.

\section{Complementary DNA (cDNA) synthesis and PCR reaction parameters}

Complementary DNA (cDNA) was synthesized using the High Capacity cDNA Synthesis Kit (Life Technologies) following the manufacturer's protocol. Briefly, $1.5 \mu \mathrm{g}$ of RNA was used to initiate synthesis in a reaction volume of $20 \mu \mathrm{l}$ (Garver et al. 2011); the reaction was diluted to a final volume of $40 \mu \mathrm{l}$ and stored at $-20^{\circ} \mathrm{C}$ until used. A previously described cDNA protocol that was initiated with $1 \mu \mathrm{g}$ RNA and included a 1:10 dilution of the final cDNA (Purcell et al. 2004) was also used for analytical validation, but this method was not used for diagnostic or field validation.

The real-time PCR step was performed using an ABI PRISM 7900HT Sequence Detection System (Life Technologies). The cycling conditions were $50^{\circ} \mathrm{C}$ for $2 \mathrm{~min}, 95^{\circ} \mathrm{C}$ for $10 \mathrm{~min}$, followed by 40 cycles of $95^{\circ} \mathrm{C}$ for $15 \mathrm{sec}$ and $60^{\circ} \mathrm{C}$ for $1 \mathrm{~min}$. Reactions contained $12 \mu \mathrm{l}$ of ABI Universal PCR Master Mix (Life Technologies) with $900 \mathrm{nM}$ of each forward and reverse primers, $200 \mathrm{nM}$ of IHNV N probe, and $200 \mathrm{nM}$ of APC probe, with $5 \mu$ l of diluted cDNA. Negative template controls and positive controls were included on each plate run. For certain comparisons, the Fast Start Universal Master Mix (Roche) and ABI Gene Expression Master Mix (Life Technologies) were used.
Tissue samples were also tested using a RT-cPCR assay targeting the central portion of the $G$ gene ('mid-G') as specified by the World Organization for Animal Health (OIE 2012). Briefly, samples were screened using the forward primer 5'-AGA GAT CCC TAC ACC AGA GAC-3' and reverse primer 5'-GGT GGT GTT GTT TCC GTG CAA-3' following the OIE protocol except that the cDNA was synthesized as a separate reaction (as described above).

\section{Analytical validation}

The analytical sensitivity and PCR efficiency of the IHNV RT-rPCR assay were evaluated using standard curves generated with (1) APC plasmid DNA, (2) cDNA derived from RNA extracted from IHNV-infected tissues and (3) cDNA derived from RNA extracted from the clarified supernatant of cultured cells infected with IHNV. Standard curves from 4 representative IHNV isolates (220-90, BC203, SRCV, and PRT, corresponding to the M, U, L, and J genogroups, respectively) were generated to compare RT-rPCR reaction efficiencies among genogroups. Standard curves consisted of 10-fold serial dilutions. Six replicates were subjected to RT-rPCR per dilution.

The IHNV RT-rPCR assay was tested for crossreactivity to 4 related fish rhabdovirus species. The specificity panel consisted of 4 isolates of VHSV (genogroups Ia, IVa, IVb and IVc) and single isolates of HIRRV, SHRV, and spring viremia of carp virus (SVCV) (Table 1). To confirm that these isolates had detectable levels of genomic material present, we used virus-specific diagnostic reverse transcriptase PCR methods developed for this study (SHRV 471F: AAG GCA GTG GAT CGA GAG TTT; SHRV 987R: CCA TGT TAA CAA TTG CGT GGT TCA) or described elsewhere (Sun et al. 2010, Garver et al. 2011, AFS 2012).

A total of 36 isolates representing the major IHNV genogroups U, M, L, E and J were tested to verify that the N gene RT-rPCR assay had universal detection across a broad geographic and phylogenetic range (Table 1 ; isolates kindly provided by Dr. G. Kurath, US Geological Survey; Dr. N. Jørgen Oleson, Technical University of Denmark; and Dr. T. Nishizawa, Chonnam University, Korea). Members of the U, M, and L genogroups can be further subdivided into phylogenetic subgroups (as shown in Table 1) with significant statistical support (Troyer et al. 2000, Garver et al. 2003, Kurath et al. 2003, Troyer \& Kurath 2003, Kelley et al. 2007). 
Table 1. Infectious hematopoietic necrosis virus (IHNV) reverse transcriptase real-time PCR (RT-rPCR) assay detection of RNA extracted from supernatant of fish cells infected with various viral isolates, including IHNV, viral hemorrhagic septicemia virus (VHSV), hirame rhabdovirus (HIRRV), snakehead rhabdovirus (SHRV), and spring viremia of carp virus (SVCV). $\mathrm{C}_{\mathrm{T}}$ : cycle threshold; CRB: Columbia River basin; bd: below detection; presence of viral RNA molecules in samples was confirmed by virus-specific primers as described in 'Materials and methods'

\begin{tabular}{|c|c|c|c|c|c|c|}
\hline $\begin{array}{l}\text { Viral } \\
\text { species }\end{array}$ & $\begin{array}{l}\text { Major } \\
\text { geno- } \\
\text { group }\end{array}$ & $\begin{array}{l}\text { Sub- } \\
\text { type }\end{array}$ & Isolate & $\begin{array}{c}\text { Geographic } \\
\text { area }\end{array}$ & $\begin{array}{l}\text { Isolation } \\
\text { year }\end{array}$ & $\begin{array}{c}\text { Mean } \\
\mathrm{C}_{\mathrm{T}}\end{array}$ \\
\hline \multirow[t]{36}{*}{ IHNV } & $\mathrm{U}$ & $\mathrm{C}$ & RB1 & CRB, USA & 1975 & 18.5 \\
\hline & $\mathrm{U}$ & $\mathrm{P}$ & BC4814 & BC, Canada & 1992 & 16.9 \\
\hline & $\mathrm{U}$ & $\mathrm{P}$ & BC203 & BC, Canada & 2002 & 19.3 \\
\hline & $\mathrm{U}$ & $\mathrm{P}$ & Auk77 & Alaska, USA & 1977 & 19.2 \\
\hline & $\mathrm{U}$ & $\mathrm{P}$ & Blk94 & WA, USA & 1994 & 18.7 \\
\hline & U & $\mathrm{P}$ & RU1 & Russia & 2000 & 19.7 \\
\hline & U & $\mathrm{P}$ & RU9 & Russia & 2001 & 17.0 \\
\hline & $\mathrm{U}$ & $\mathrm{C}$ & LNFH10 & WA, USA & 2010 & 19.0 \\
\hline & $\mathrm{U}$ & $\mathrm{C}$ & DW10 & ID, USA & 2010 & 18.3 \\
\hline & $\mathrm{U}$ & Asia & Shiz82 & Japan & 1982 & 22.8 \\
\hline & M & $\mathrm{N}$ & LR80 & CRB, USA & 1980 & 19.0 \\
\hline & M & A & WRAC & ID, USA & 1982 & 19.9 \\
\hline & M & B & $220-90$ & ID, USA & 1990 & 17.5 \\
\hline & M & $\mathrm{C}$ & C30 & ID, USA & 1991 & 18.0 \\
\hline & M & $\mathrm{D}$ & Mer95 & CRB, WA & 1995 & 18.6 \\
\hline & M & $\mathrm{D}$ & Tan02 & WA, USA & 2002 & 19.6 \\
\hline & M & $\mathrm{D}$ & QTS-07 & WA, USA & 2007 & 19.6 \\
\hline & $\mathrm{M}$ & $\mathrm{D}$ & DW09 & ID, USA & 2009 & 21.0 \\
\hline & $\mathrm{L}$ & $\mathrm{I}$ & C18 & CA, USA & 1991 & 23.1 \\
\hline & L & II & SRCV & CA, USA & 1966 & 19.0 \\
\hline & $\mathrm{L}$ & II & FR3100 & CA, USA & 2000 & 22.6 \\
\hline & E & - & $32 / 87$ & France & 1987 & 22.9 \\
\hline & E & - & N61 & France & Unknown & 21.9 \\
\hline & E & - & 8814 & France & Unknown & 22.1 \\
\hline & E & - & $55 / 94$ & Austria & 1994 & 19.1 \\
\hline & E & - & $02-248 E$ & Slovenia & 2002 & 29.4 \\
\hline & E & - & 4008 & Italy & 1989 & 24.5 \\
\hline & E & - & DF04/99 & Germany & 1999 & 21.9 \\
\hline & E & - & TR & Turkey & Unknown & 18.7 \\
\hline & $\mathrm{J}$ & - & ChAb76 & Japan & 1976 & 19.5 \\
\hline & $\mathrm{J}$ & - & RtNag76 & Japan & 1976 & 19.6 \\
\hline & $\mathrm{J}$ & - & RtShiz06s & Japan & 2006 & 20.7 \\
\hline & $\mathrm{J}$ & - & RtNag06a & Japan & 2006 & 20.0 \\
\hline & $\mathrm{J}$ & - & RtShiz06a & Japan & 2006 & 19.5 \\
\hline & $\mathrm{J}$ & - & PRT & Korea & 1991 & 20.3 \\
\hline & $\mathrm{J}$ & - & RtUi02 & Korea & 2002 & 19.0 \\
\hline \multirow[t]{4}{*}{ VHSV } & I & $\mathrm{a}$ & DK3295B & Denmark & 1986 & $\mathrm{bd}$ \\
\hline & IV & a & 99-292 & BC, Canada & 1999 & $\mathrm{bd}$ \\
\hline & IV & $\mathrm{b}$ & MI03 & Great Lakes, USA & 2003 & $\mathrm{bd}$ \\
\hline & IV & $\mathrm{C}$ & NB & NB, Canada & 2000 & bd \\
\hline HIRRV & - & - & $8401 \mathrm{H}$ & Japan & 1984 & bd \\
\hline SHRV & NA & NA & NA & Southeast Asia & 1986 & $\mathrm{bd}$ \\
\hline SVCV & I & $\mathrm{a}$ & $\mathrm{NC}$ & $\mathrm{NC}, \mathrm{USA}$ & 2002 & $\mathrm{bd}$ \\
\hline
\end{tabular}

The within-run repeatability of the universal IHNV RT-rPCR was estimated by performing 10 replicate wells (in the same run) of 3 samples representing different viral load levels. To measure the between-run repeatability of each assay, the 3 samples represent- ing different copy number concentrations were tested in 3 separate runs on different days. Coefficient of variation (CV) was calculated as standard deviation/mean.

\section{Diagnostic validation}

Fifty steelhead trout Oncorhynchus mykiss (approximately $120 \mathrm{~g}$ ) were injected with $100 \mu \mathrm{l}$ of medium containing $5 \times 10^{4}$ plaque forming units per fish of M genogroup IHNV (Strain QTS-07). An additional 50 steelhead trout were injected with $100 \mu \mathrm{l}$ of medium alone. Fish were held at $12{ }^{\circ} \mathrm{C}$ and sampled $72 \mathrm{~h}$ post injection. Three $30 \mathrm{mg}$ aliquots of kidney were aseptically removed and stabilized in RNA later. RNA was extracted from anterior kidney samples for RT-rPCR analysis, as described above. All remaining kidney was homogenized and stored at $-80^{\circ} \mathrm{C}$. Virological analysis of the homogenized kidney diluted to a final concentration of 1:40 (w/v) was performed as previously described (Batts \& Winton 1989), except that results were interpreted as positive or negative rather than as a titer. Diagnostic sensitivity (DSe), diagnostic specificity (DSp), likelihood ratios of a positive $(\mathrm{L}+)$ and negative (LR-) result and the diagnostic odds ratio (DOR) were calculated directly (Caraguel et al. 2011) or using EpiTools Online Epidemiological software (http://epitools. ausvet.com.au). Test results are categorized as TP (true positives), FN (false negatives), TN (true negatives), and FP (false positives); cells with zero values were corrected for continuity by adding 0.5. Calculations were as follows: $\mathrm{DSe}=\mathrm{TP} /(\mathrm{TP}+\mathrm{FN}) ; \mathrm{DSp}=\mathrm{TN} /$ $(\mathrm{FP}+\mathrm{TN}) ; \mathrm{LR}+=\mathrm{DSe} /(1-\mathrm{DSp}) ; \mathrm{LR}-=$ $(1-\mathrm{DSe}) / \mathrm{DSp} ; \mathrm{DOR}=\mathrm{LR}+/ \mathrm{LR}-$.

\section{Field validation}

A random sample $(\mathrm{N}=60)$ of juvenile steelhead trout was collected from a hatchery raceway at Dwor- 
shak National Fish Hatchery (NFH) (Orofino, ID) that was experiencing active IHN disease at the time of sampling. Standard virological testing (excluding blind passage) (AFS 2012) was performed at the US Fish and Wildlife, Idaho Fish Health Center on individual samples. In all cases, a duplicate kidney tissue was collected and stabilized in RNAlater, shipped to the Western Fisheries Research Center and analyzed using the IHNV RT-rPCR assay.

\section{Reproducibility and ruggedness}

Reproducibility was evaluated by inter-laboratory comparison. Two kidney tissue aliquots $(\mathrm{N}=50$ infected; $\mathrm{N}=50$ non-infected) generated during the laboratory challenges described above were sent to the Fisheries and Oceans Canada Pacific Biological Station (DFO-PBS) (Nanaimo, BC). These samples were subjected to IHNV RT-rPCR analysis but the protocol utilized at DFO-PBS varied slightly from the methods described above: (1) RNA was extracted using Trizol (Invitrogen) as previously described (Garver et al. 2011) and (2) the real-time PCR was performed using the Mx3000p instrument (Stratagene).

\section{RESULTS}

\section{Assay development}

Alignment of the $\mathrm{N}$ gene nucleotide sequences from different IHNV isolates revealed an $80 \mathrm{bp}$ region suitable for universal primer and probe design. There were no nucleotide mismatches spanning the primer and probe sequences among the IHNV isolates examined while both HIRRV and VHSV had more than 12 nucleotide mismatches within the target sequences of the IHNV primers and probe. Three primer/probe sets were initially tested using RNA derived from IHNV-infected tissues, and the best results were obtained with the set described herein (data not shown). We observed no discernible effect on assay sensitivity (measured by a shift in cycle threshold, $\mathrm{C}_{\mathrm{T}}$ ) when the fluorescent VIC@-labeled APC probe was included in the IHNV RT-rPCR reaction (data not shown). When included in the reaction, the APC probe is designed to detect false positive results due to cross-contamination by the plasmid DNA positive control. We also tested whether the TaqMan (® Exogenous Internal Positive Control (IPC) Reagents (also a VIC-labeled probe; Life Technolo- gies) impacted the IHNV RT-rPCR assay sensitivity and found no discernible effect (data not shown). When included in the reaction, the IPC reagent detects PCR inhibition that may lead to false negative test results.

\section{Analytical validation}

The slopes of the lines obtained when serial 10-fold dilutions of a standard template were analyzed ranged from -3.2 to -3.5 depending on template type (Figs. 2 \& 3); these results indicated similar PCR reaction efficiencies regardless of template type. The IHNV RT-rPCR assay reliably detected APC plasmid DNA copies ranging from $5 \times 10^{7}$ to 5 copies per reaction (Fig. 2A). We typically obtained poorer PCR efficiencies with RNA transcribed in vitro from the APC (data not shown) and did not pursue using this material as a control. A cDNA sample derived from the anterior kidney of an IHNV infected trout with an initial $C_{T}$ value of 27.0 (approximately $7.0 \times 10^{3}$ copies per reaction) was reliably detected (4 of 4 replicates)

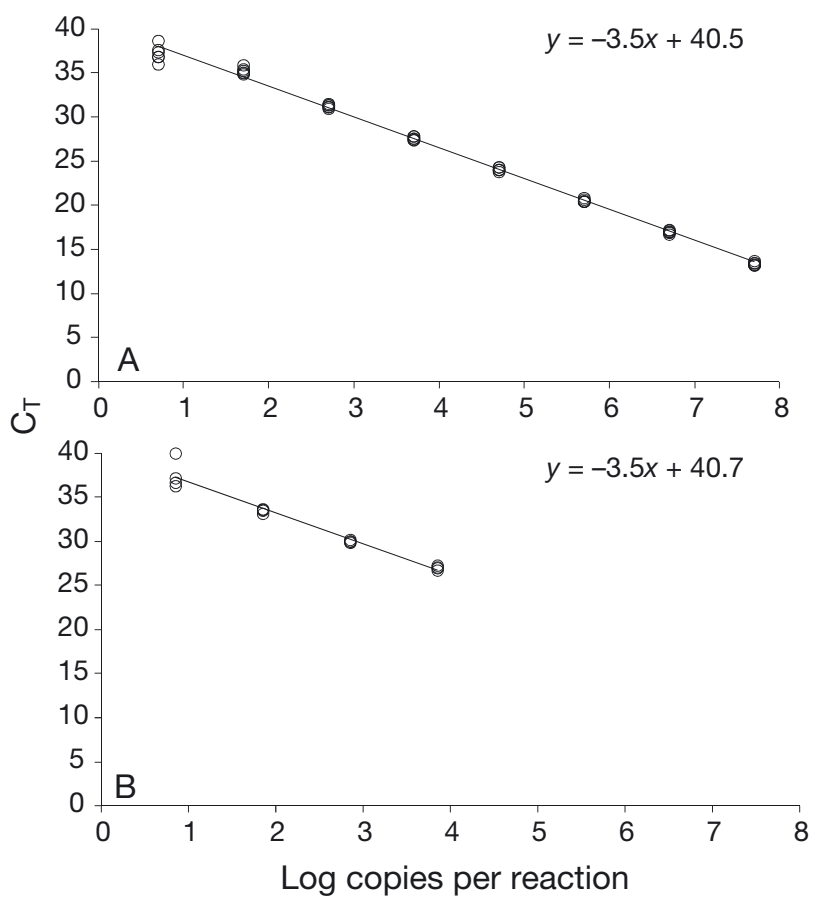

Fig. 2. Standard curves using 10-fold serially diluted cDNA were subjected to infectious hematopoietic necrosis virus (IHNV) reverse transcriptase real-time PCR (RT-rPCR). Four replicates were included per dilution for each RT-rPCR reaction. (A) Artificial positive control (APC) plasmid DNA (5 $\times$ $10^{7}$ to 5 copies per reaction) and (B) anterior kidney cDNA derived from a rainbow trout infected with IHNV strain 220-

$90\left(7 \times 10^{3}\right.$ to 7 copies per reaction). $\mathrm{C}_{\mathrm{T}}$ : cycle threshold 
in serial 10-fold dilutions to a lower limit of an estimated 70 copies per reaction; the final dilution containing an estimated 7 copies per reaction produced detectable amplification in 3 of 4 technical replicates (Fig. 2B). We also assessed whether representatives of different IHNV genogroups were detected with similar sensitivity by the RT-rPCR assay. Template cDNA from U isolate BC203, M isolate 220-90, L isolate SRCV and J isolate PRT (Table 1) which had initial $\mathrm{C}_{\mathrm{T}}$ values ranging from 18.3 to 20.8 (corresponding to approximately $2.3 \times 10^{6}$ to $8.1 \times 10^{5}$ copies per reaction) were subjected to 5 serial, 10 -fold dilutions. The reaction efficiencies varied from -3.2 to -3.4 and the $y$-intercept values varied from 38.9 to 39.5, indicating similar limits of detection for different genogroups (Fig. 3).

A panel of 36 IHNV isolates was selected to represent the phylogenetic range of IHNV, and included both historical and newly emergent strains (Table 1). All isolates were detected by the assay and $\mathrm{C}_{\mathrm{T}}$ values ranged from 16.9 to 29.4 ; this $\mathrm{C}_{\mathrm{T}}$ range was observed because virus titer was not standardized before testing, and does not reflect differential assay sensitivity.
The IHNV RT-rPCR did not yield detectable amplification when cDNA template from VHSV (genogroups Ia, IVa, IVb, IVc), HIRRV, SHRV or SVCV RNA was used (Table 1); the presence of amplifiable viral RNA in these samples was confirmed with pathogen-specific primers. Thus, the empirical testing of the RT-rPCR assay indicated good inclusivity capable of reacting with isolates representing all 5 major IHNV genogroups and good exclusivity of closely related viral strains.

Three kidney cDNA samples that tested positive by the IHNV RT-rPCR with mean $\mathrm{C}_{\mathrm{T}}$ values of 26.6, 31.1 and 35.8 were evaluated for within- and betweenrun repeatability. Each sample was run 10 times on the sample plate and CV estimated for each sample was $0.6 \%, 0.5 \%$ and $1.0 \%$, respectively. The 3 samples were also each subjected to 3 independent runs and the between-run CV estimated for each sample was $0.8 \%, 0.4 \%$ and $1.3 \%$ respectively. The highest $\mathrm{CV}$ values were observed when using the sample that had a mean $\mathrm{C}_{\mathrm{T}}$ value of 35.8, indicating that increased variation was associated with lower viral copy number.
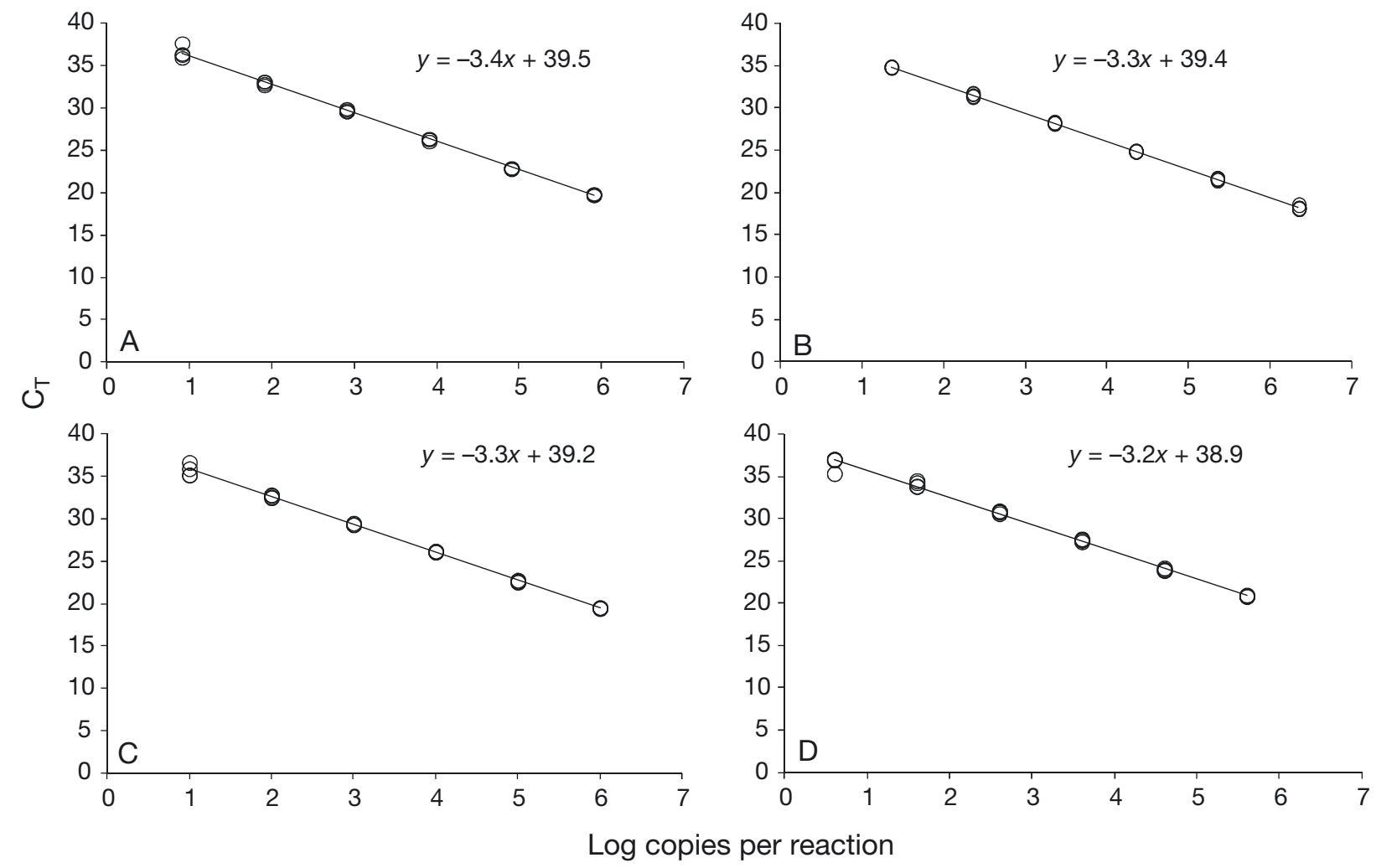

Fig. 3. Analytical sensitivity of the infectious hematopoietic necrosis virus (IHNV) reverse transcriptase real-time PCR (RT-rPCR) assay using 4 virus strains representing various genogroups of IHNV as template for the reaction. (A) U genogroup (strain BC203), (B) M genogroup (strain 220-90), (C) L genogroup (strain SRCV), and (D) J genogroup (strain PRT). Six technical replicates were performed per dilution. $\mathrm{C}_{\mathrm{T}}$ : cycle threshold 


\section{Diagnostic validation}

Detection of IHNV in kidney tissue by cell culture, RT-CPCR and RT-rPCR was compared using a group of 100 steelhead in which half the fish were injected with medium and the other half with IHNV (50\% predicted prevalence of infection). All fish injected with medium (assumed to be the 'true negatives') tested negative by all 3 methods; diagnostic specificity was calculated as 1.00 for all 3 diagnostic tests. Among the 50 fish injected with IHNV (assumed to be the 'true positives'), all fish tested positive by RTrPCR, but only a subset tested positive by culture and RT-cPCR (Table 2). Culture produced 42 positive test results $(42 \%$ prevalence); DSe was calculated as 0.84 with positive and negative likelihood ratios of 84.0 and 0.16 , respectively. The RT-cPCR produced 29 positive test results (29\% prevalence); DSe was estimated to be 0.58 with positive and negative likelihood ratios of 58.0 and 0.42 , respectively. The RTrPCR produced 50 positive test results $(50 \%$ prevalence); DSe was estimated to be 1.00 with positive and negative likelihood ratios of 99.0 and 0.01, respectively. The RT-rPCR had the highest diagnostic odds ratio (DOR $=9901)$, followed by culture ( DOR $=520$ ), with the single round RT-cPCR having the lowest value $(\mathrm{DOR}=137)$ (Table 2). The samples that tested negative by cell culture or RT-CPCR had overall higher mean $C_{T}$ values than samples that tested positive by these 2 methods (Fig. 4).

\section{Field validation}

IHNV detection by RT-rPCR was compared to cell culture using samples randomly collected during a

Table 2. Estimated diagnostic sensitivity (DSe), diagnostic specificity (DSp), and likelihood ratio of a positive result (LR+), likelihood ratio of a negative result (LR-) and diagnostic odds ratio (DOR) for infectious hematopoietic necrosis virus (IHNV) detection using 3 diagnostic tests: virus isolation in cell culture, G gene reverse transcriptase conventional PCR (RT-cPCR) and N gene reverse transcriptase real-time PCR (RT-rPCR). Test results are categorized as TP (true positives), FN (false negatives), TN (true negatives), and FP (false positives)

\begin{tabular}{|c|c|c|c|c|c|c|c|c|c|}
\hline Test & $\mathrm{TP}$ & FN & TN & FP & $\begin{array}{c}\text { DSe } \\
(95 \% \mathrm{CI})\end{array}$ & $\begin{array}{c}\text { DSp } \\
(95 \% \mathrm{CI})\end{array}$ & LR+ & LR- & DOR \\
\hline Culture & 42 & 8 & 50 & 0 & $\begin{array}{c}0.84 \\
(0.71,0.93)\end{array}$ & $\begin{array}{c}1.00 \\
(0.93,1.00)\end{array}$ & 84 & 0.16 & 520 \\
\hline RT-cPCR & 29 & 21 & 50 & 0 & $\begin{array}{c}0.58 \\
(0.43,0.71)\end{array}$ & $\begin{array}{c}1.00 \\
(0.93,1.00)\end{array}$ & 58 & 0.42 & 137 \\
\hline RT-rPCR & 50 & 0 & 50 & 0 & $\begin{array}{c}1.00 \\
(0.93,1.00)\end{array}$ & $\begin{array}{c}1.00 \\
(0.93,1.00)\end{array}$ & 99 & 0.01 & 9901 \\
\hline
\end{tabular}

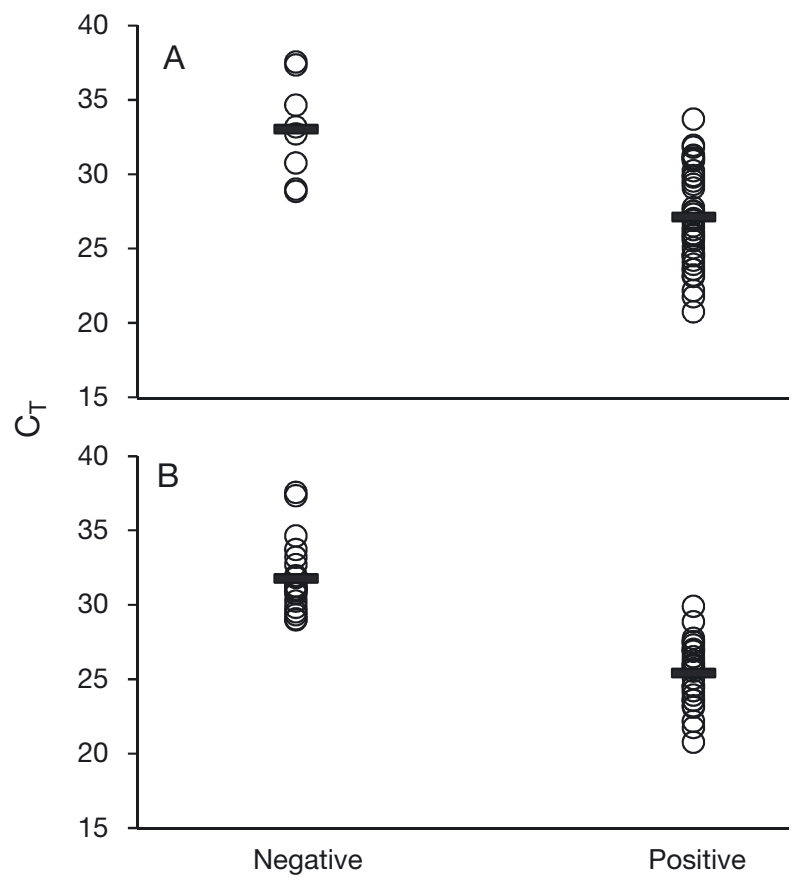

Fig. 4. Distribution of cycle threshold $\left(\mathrm{C}_{\mathrm{T}}\right)$ values obtained by infectious hematopoietic necrosis virus reverse transcriptase real-time PCR (RT-rPCR) for samples that tested negative or positive by (A) cell culture or (B) reverse transcriptase conventional PCR (RT-cPCR)

juvenile steelhead IHNV epizootic at Dworshak National Fish Hatchery. IHNV prevalence in kidney tissues derived from randomly sampled steelhead was estimated at $10 \%$ by cell culture (6 of 60 fish tested) and $70 \%$ by the RT-rPCR assay (42 of 60 fish tested). The RT-rPCR test results had $40 \%$ overall observed agreement with cell culture. There were no samples that tested culture positive but RT-rPCR negative. The kappa statistic was estimated at 0.09 (95\% CI 0.01-0.17), which indicated only slight agreement between tests based on a commonly used interpretation criteria (Smith 2006).

\section{Reproducibility and ruggedness}

Duplicate tissue samples from laboratory-challenged steelhead trout were sent blind to Department of Fisheries and Oceans Canada, Pacific Biological Station (DFO-PBS) to evaluate both repeatability and reproducibility of the IHNV RT-rPCR assay. Results were in $100 \%$ agreement between laboratories (reproducibility 
between WFRC and DFO-PBS) and within the laboratory (repeatability within DFO-PBS), with the 50 non-injected 'true negative' fish testing negative and the 50 'true positive' fish testing positive.

Testing within the WFRC laboratory found that the RT-rPCR was rugged to substitutions in master mix with similar results obtained with various master mix formulations (Fast start Real-Time PCR Master Mix, ABI TaqMan® Universal Master Mix and ABI TaqMan® Gene Expression Master Mix; data not shown). Limited testing with the ABI TaqMan ${ }^{\circledR}$ RTPCR Master Mix, which combines the reverse transcriptase and PCR into a 1-step reaction, also showed promising results indicating that the assay could be adapted to a 1-step procedure.

\section{DISCUSSION}

Here, we report the development of an RT-rPCR assay for the detection of IHNV RNA and validation of this assay for purposes that could include surveillance, rapid diagnosis or confirmation of cell-culture derived isolates. The IHNV RT-rPCR assay had high analytical sensitivity, analytical specificity and repeatability. The reliable limit of detection was between 5 and $70 \mathrm{~N}$ gene copies per reaction (depending on template), and this high analytical sensitivity was observed regardless of viral genotype. The RTrPCR assay yielded highly repeatable results both within and between assay runs, and highly reproducible results both within and between laboratories. No detectable amplification was observed when templates derived from related fish rhabdoviruses were used in the reaction. The RT-rPCR assay was also able to reliably detect 30 representative IHNV strains that span the host, geographic and phylogenetic ranges of IHNV.

Controls are samples that ensure the validity of test results and can increase the likelihood of detecting false positive or false negative results. Positive control materials can be a source of laboratory contamination, particularly if they are in high copy number (Purcell et al. 2011). Early in the development of the IHNV RT-rPCR assay, we synthesized an APC that contained an arbitrary tag sequence, utilizing a previously reported APC design for Infectious salmon anemia virus (Snow et al. 2009). The APC tag sequence can be detected by a separate probe that was included with the IHNV primers and FAM-labeled probe mixture. If a sample well tests positive for both the IHNV sequence and the tag sequence then it would be presumed to be falsely positive due to cross-contamination by the APC plasmid DNA, and retested. In certain instances, users may be more concerned with false negative results due to PCR inhibition (relative to false positive results). Inclusion of a commercial IPC in the IHNV RT-rPCR reaction that detects PCR inhibition did not impact assay sensitivity. Unfortunately, it is not possible to conduct the IPC multiplex reaction and also include the IHNV APC probe in each reaction because both rely on a VIC@-labeled probe. Thus, assay users must prioritize the detection of either false positives or false negatives. Different reporter dyes could be used, but additional validation would be required to ensure no loss of analytical sensitivity or specificity when conducting a 'triplex' rPCR reaction.

The APC DNA was also used to construct a standard curve that yielded similar PCR reaction efficiencies as serial dilutions of kidney cDNA. In this study, the APC DNA was quantified to determine gene copy number (e.g. 'quantitative PCR') in order to define the limit of detection as part of the validation process. However, for routine diagnostic use, we do not recommend quantitative PCR because of the difficulty of standardizing copy number across laboratories using different procedures and instruments. In general, most diagnostic centers are interested in using real-time PCR for obtaining a positive or negative test result. Although the $\mathrm{C}_{\mathrm{T}}$ values may be useful as categorical estimates of viral copy number (e.g. high, medium and low), comparing results across laboratories should be done cautiously as $\mathrm{C}_{\mathrm{T}}$ values can vary among instrument platforms and will change depending on analysis parameters (Purcell et al. 2011).

The threshold value selected for a test result to be considered positive or negative must be clearly defined for any diagnostic assay (OIE 2012). A variety of approaches have been used to define the threshold cut-off values for real-time PCR reactions, including both analytical and epidemiological approaches (Caraguel et al. 2011). The analytical approach most commonly used is either interpreting detectable amplification as a positive, or defining an arbitrary $\mathrm{C}_{\mathrm{T}}$ cut-off value (e.g. mean $\mathrm{C}_{\mathrm{T}}<38$ ). Ideally, the choice of cut-off should consider the fitness of purpose and whether it is a priority to minimize false positive or false negative test results. Here, we used analytical interpretation criteria as follows: (1) detectable amplification within 40 cycles in both technical replicates was considered a positive, (2) no detectable amplification in both technical replicates was considered a negative, and (3) detectable amplification in only 1 of 2 technical replicates was suspect 
but scored as a negative. Depending on the implications of a positive or negative test result, samples that yielded a suspect result could be retested using a higher number of technical replicates (e.g. 4 replicates) to clarify test results.

Diagnostic performance of the IHNV RT-rPCR test was evaluated using laboratory-reared fish to create specimens of known infection status, and the assay was compared to existing diagnostic methods, including cell culture and a single-round RT-cPCR test. The DSp of all 3 tests was 100\% with no false positives observed for any method. The DSe varied among the 3 tests with the RTrPCR showing the highest DSe $(100 \%)$, followed by cell culture (84\%) and the single round RTCPCR (58\%). The high DOR for the RT-rPCR relative to the other tests indicates that the RT-rPCR has a higher likelihood of correctly classifying a sample as positive or negative.

The single-round RT-cPCR targets the G gene, which is expressed at a lower transcript level than the N gene targeted by the RT-rPCR because of transcriptional attenuation in rhabdoviruses (Rose \& Schubert 1987), which likely decreased assay sensitivity. We compared estimated viral copy numbers obtained using the N gene RT-rPCR to a previously published G gene RT-qPCR (Purcell et al. 2006) and found that the $\mathrm{N}$ gene assay estimated about 5-fold higher copy number than the $\mathrm{G}$ gene assay (data not shown). Typically, the RT-cPCR test used here is recommended for cell culture confirmation (AFS 2012, OIE 2012) where the viral copy number would presumably be high. The RT-cPCR test would rarely be used as a primary surveillance method for tissue samples unless combined with a nested internal set of PCR primers to increase analytical sensitivity.

In the present study using samples from laboratory challenged fish, the estimated DSe of the RT-rPCR was higher than cell culture (100 vs. $84 \%$ ), but these estimates did not differ significantly as evidenced by overlapping $95 \%$ confidence intervals. A number of studies have indicated that RT-rPCR can be more sensitive than culture in detecting fish rhabdoviruses. A study comparing the IHNV G gene RTrPCR to plaque assay found on average 8000 genome copies compared to 1 plaque forming unit, respectively (Purcell et al. 2006). For VHSV, the equivalent of approximately $10000 \mathrm{~N}$ gene copies per $\mu \mathrm{g}$ RNA, determined by RT-qPCR analysis, must be present in a sample to be reliably isolated by cell culture (Hope et al. 2010). Here, 8 samples from the laboratory study tested positive by RT-rPCR but negative by cell culture; these samples had $\mathrm{C}_{\mathrm{T}}$ values that ranged from 37.6 to 30.0 , which approximates to 36 to $5000 \mathrm{~N}$ gene copies per $\mu \mathrm{g}$ RNA.

Field evaluation of the RT-rPCR was performed using fish sampled during an IHNV epizootic in juvenile steelhead in 2011. The true infection status of each animal was not known, so we were limited in our analysis to assessing agreement between tests. The IHNV RT-rPCR assay yielded a higher prevalence of positive test results than virus culture, with $40 \%$ agreement between the 2 tests. The strength of this agreement, as measured by kappa statistic, was slight. However, the kappa statistic can be biased lower even with moderate agreement when infection prevalence is very low or very high (Feinstein \& Cicchetti 1990), as occurred in this study with prevalence estimated at $10 \%$ by cell culture.

The laboratory and field studies presented here indicated that the RT-rPCR had higher sensitivity than virus culture. This property may increase concerns that positive results are due to laboratory contamination and make confirmation by secondary methods difficult (Purcell et al. 2011). This concern can be minimized with proper use of positive and negative controls, quality assurance measures and laboratory proficiency testing. Nonetheless, isolation of the virus by cell culture has unique advantages and continues to be the most accepted method for IHNV diagnosis. The results presented here predict that virus culture confirmation of RT-rPCR results should be possible given sufficient viral load.

All diagnostic assays must be empirically evaluated to verify that the test performs optimally in the population of interest and, following deployment, should be continually monitored to ensure optimal test performance. A previous study that compared virus isolation in cell culture to a SYBR green based RT-rPCR assay targeting the IHNV N gene observed much higher prevalence by cell culture (92\%) than by RT-rPCR ( $42 \%)$ in a sample collection of naturally infected rainbow trout Oncorhynchus mykiss from a farmed population (Idaho, USA) (Dhar et al. 2008). An unusually high level of genetic diversity among IHNV isolates is known to exist within the Idaho rainbow trout aquaculture industry (Troyer et al. 2000, Troyer \& Kurath 2003). Our in silico analysis of the primers used by Dhar et al. (2008) found nucleotide mismatches in the forward and reverse directions that could lower assay sensitivity or specificity. Furthermore, the study did not discuss the inclusion of an IPC to assess whether PCR inhibition was also occurring. Nonetheless, the suitability of any PCRbased assay as the sole screening method in populations anticipated to have high levels of IHNV genetic 
diversity would require empirical evaluation. Furthermore, both acute and chronic forms of IHN disease have been described in rainbow trout (Amend 1975, LaPatra et al. 1995) and more study would be needed to assess diagnostic sensitivity of the RTrPCR to detect both disease forms.

Complete validation of a diagnostic test should include evaluating the test in multiple laboratories (reproducibility), as well as assessing how changes in assay parameters and reagents influence test performance (ruggedness). Inter-laboratory comparison can also be highly useful during the assay development and optimization phase. For instance, during the initial assay development steps conducted at the WFRC, our standard protocol was to dilute cDNA template such that 25 to $50 \mathrm{ng}$ was used in the final real-time PCR reaction. However, the standard operating procedure at the DFO-PBS laboratory used approximately $190 \mathrm{ng}$ in the final real-time PCRreaction, and this higher template concentration improved analytical sensitivity with no indication of PCR inhibition. Thus, testing of laboratory-challenged samples for diagnostic validation purposes was done with the DFO-PBS protocol utilizing higher template concentrations. Testing of duplicate samples at the WFRC and DFO-PBS laboratories indicated $100 \%$ agreement in test results with all results showing a perfect match to the expected results. Furthermore, the DFO-PBS also performed a within-laboratory comparison by testing 2 duplicate tissue samples and also observed perfect agreement in the results. Others have reported that master mix formulations may impact assay sensitivity (Elliott et al. 2013). However, we found no significant difference in IHNV RT-rPCR results when we compared 3 different master mix formulations - with the exception of a 1-step master mix. Although preliminary, the overall results of within and between laboratory comparisons indicated that the assay is relatively rugged to changes in real-time PCR instrumentation, extraction methods and master mix formulation. Further evaluation of reproducibility and ruggedness would require expanding the number of laboratories included in the inter-laboratory testing scheme.

Real-time PCR has become the methodology of choice for surveillance of terrestrial animal pathogens in the US National Animal Health Laboratory Network and the Canadian Animal Health Surveillance Network (Purcell et al. 2011). In Canada, the National Aquatic Animal Health Plan (NAAHP) and the associated National Aquatic Animal Health Laboratory System are in the process of being fully implemented and real-time PCR methodology is the proposed method for surveillance of the major program pathogens. The USA has only partially implemented the NAAHP and the surveillance methods have not been defined, but it is likely that real-time PCR will be included in the testing algorithim for at least some of the program pathogens. The universal IHNV RT-rPCR developed and validated herein is a suitable test for IHNV surveillance purposes.

Acknowledgements. We thank Drs. G. Kurath, N. Jørgen Olesen and T. Nishizawa for contributing viral strains. Ms. M. Waldram provided technical assistance. Dr. D. Elliott provided assistance with statistical analyses. Funding was provided by Fisheries and Aquatic Ecosystem Resources Program of the US Geological Survey, the US Department of Agriculture, Animal and Plant Health Inspection Services, US Fish and Wildlife Service and Department of Fisheries and Oceans Canada. All animal experiments were conducted under a protocol approved by the Institutional Animal Care and Use Committee of the Western Fisheries Research Center. The use of trade, firm, or corporation names in this publication is for the information and convenience of the reader. Such use does not constitute an official endorsement or approval by the US Department of Interior, the US Geological Survey, US Fish and Wildlife Service, or Department of Fisheries and Oceans Canada of any product or service to the exclusion of others that may be suitable.

\section{LITERATURE CITED}

AFS (2012) Suggested procedures for the detection and identification of certain finfish and shellfish pathogens. American Fisheries Society, Bethesda, MD

Amend DF (1975) Detection and transmission of infectious hematopoietic necrosis virus in rainbow trout. J Wildl Dis 11:471-478

Amend DF, Yasutake WT, Mead RW (1969) A hematopoietic virus disease of rainbow trout and sockeye salmon. Trans Am Fish Soc 98:796-804

> Anderson ED, Mourich DV, Fahrenkrug SC, La Patra SE, Shepard J, Leong JC (1996) Genetic immunization of rainbow trout (Oncorhynchus mykiss) against infectious hematopoietic necrosis virus. Mol Mar Biol Biotechnol 5: $114-122$

Arakawa CK, Deering RE, Higman KH, Oshima KH, O'Hara PJ, Winton JR (1990) Polymerase chain reaction (PCR) amplification of a nucleoprotein gene sequence of infectious hematopoietic necrosis virus. Dis Aquat Org 8: $165-170$

Batts WN, Winton JR (1989) Enhanced detection of infectious hematopoietic necrosis virus and other fish viruses by pretreatment of cell monolayers with polyethylene glycol. J Aquat Anim Health 1:284-290

Bootland LM, Leong JC (2009) Infectious haematopoietic necrosis virus. In: Woo PTK, Bruno DW (eds) Fish diseases and disorders, Vol 3. CAB International, Wallingford, p 66-109

> Caraguel CGB, Stryhn H, Gagné N, Dohoo IR, Hammell KL (2011) Selection of a cutoff value for real-time polymerase chain reaction results to fit a diagnostic purpose: analytical and epidemiological approaches. J Vet Diagn Invest 23:2-15 
Dhar AK, Bowers RM, Licon KS, LaPatra SE (2008) Detection and quantification of infectious hematopoietic necrosis virus in rainbow trout (Oncorhynchus mykiss) by SYBR Green real-time reverse transcriptase-polymerase chain reaction. J Virol Methods 147: 157-166

Elliott DG, Applegate LJ, Murray AL, Purcell MK, McKibben CL (2013) Bench-top validation testing of selected immunological and molecular Renibacterium salmoninarum diagnostic assays by comparison with quantitative bacteriological culture. J Fish Dis 36: 779-809

Engelking HM, Leong JC (1989) Glycoprotein from infectious hematopoietic necrosis virus (IHNV) induces protective immunity against five IHNV types. J Aquat Anim Health 1:291-300

Enzmann PJ, Kurath G, Fichtner D, Bergmann SM (2005) Infectious hematopoietic necrosis virus: monophyletic origin of European isolates from North American Genogroup M. Dis Aquat Org 66:187-195

Enzmann PJ, Castric J, Bovo G, Thiery R, Fichtner D, Schütze H, Wahli T (2010) Evolution of infectious hematopoietic necrosis virus (IHNV), a fish rhabdovirus, in Europe over 20 years: implications for control. Dis Aquat Org 89:9-15

Feinstein AR, Cicchetti DV (1990) High agreement but low kappa: I. The problems of two paradoxes. J Clin Epidemiol 43:543-549

Fijan N, Sulimanović D, Bearzotti M, Muzinić D and others (1983) Some properties of the epithelioma papulosum cyprini (EPC) cell line from carp Cyprinus carpio. Ann Inst Pasteur E Virol 134:207-220

> Garver KA, Troyer RM, Kurath G (2003) Two distinct phylogenetic clades of infectious hematopoietic necrosis virus overlap within the Columbia River basin. Dis Aquat Org 55:187-203

> Garver KA, Hawley LM, McClure CA, Schroeder T and others (2011) Development and validation of a reverse transcription quantitative PCR for universal detection of viral hemorrhagic septicemia virus. Dis Aquat Org 95: 97-112

> Hope KM, Casey RN, Groocock GH, Getchell RG, Bowser PR, Casey JW (2010) Comparison of quantitative RT-PCR with cell culture to detect viral hemorrhagic septicemia virus (VHSV) IVb infections in the Great Lakes. J Aquat Anim Health 22:50-61

> Johansson T, Einer-Jensen K, Batts W, Ahrens P and others (2009) Genetic and serological typing of European infectious haematopoietic necrosis virus (IHNV) isolates. Dis Aquat Org 86:213-221

Kelley GO, Bendorf CM, Yun SC, Kurath G, Hedrick RP (2007) Genotypes and phylogeographical relationships of infectious hematopoietic necrosis virus in California, USA. Dis Aquat Org 77:29-40

Kim WS, Oh MJ, Nishizawa T, Park JW, Kurath G, Yoshimizu M (2007) Genotyping of Korean isolates of infectious hematopoietic necrosis virus (IHNV) based on the glycoprotein gene. Arch Virol 152:2119-2124

Kurath G (2012) Fish novirhabdoviruses. In: Dietzgen RG, Kuzmin IV (eds) Rhabdoviruses: molecular taxonomy, evolution, genomics, ecology, host-vector interactions, cytopathology and control. Caister Academic Press, Wymondham, p 89-116

Kurath G, Leong JC (1985) Characterization of infectious hematopoietic necrosis virus mRNA species reveals a nonvirion rhabdovirus protein. J Virol 53:462-468
Kurath G, Ahern KG, Pearson GD, Leong JC (1985) Molecular cloning of the six mRNA species of infectious hematopoietic necrosis virus, a fish rhabdovirus, and gene order determination by R-loop mapping. J Virol 53: 469-476

Kurath G, Garver KA, Troyer RM, Emmenegger EJ, EinerJensen K, Anderson ED (2003) Phylogeography of infectious haematopoietic necrosis virus in North America. J Gen Virol 84:803-814

LaPatra SE, Lauda KA, Jones GR, Walker SC, Shewmaker BS, Morton AW (1995) Characterization of IHNV isolates associated with neutrotropism. Vet Res 26:433-437

Liu Z, Teng Y, Liu H, Jiang Y and others (2008) Simultaneous detection of three fish rhabdoviruses using multiplex real-time quantitative RT-PCR assay. J Virol Methods 149:103-109

> Morzunov SP, Winton JR, Nichol ST (1995) The complete genome structure and phylogenetic relationship of infectious hematopoietic necrosis virus. Virus Res 38: 175-192

Nishizawa T, Kinoshita S, Kim WS, Higashi S, Yoshimizu M (2006) Nucleotide diversity of Japanese isolates of infectious hematopoietic necrosis virus (IHNV) based on the glycoprotein gene. Dis Aquat Org 71:267-272

OIE (2012) Manual of diagnostic tests for aquatic animals. World Organization of Animal Health, Paris. Available at www.oie.int/international-standard-setting/aquaticmanual/access-online/

Overturf K, LaPatra S, Powell M (2001) Real-time PCR for the detection and quantitative analysis of IHNV in salmonids. J Fish Dis 24:325-333

Purcell MK, Kurath G, Garver KA, Herwig RP, Winton JR (2004) Quantitative expression profiling of immune response genes in rainbow trout following infectious haematopoietic necrosis virus (IHNV) infection or DNA vaccination. Fish Shellfish Immunol 17:447-462

Purcell MK, Hart SA, Kurath G, Winton JR (2006) Strandspecific, real-time RT-PCR assays for quantification of genomic and positive-sense RNAs of the fish rhabdovirus infectious hematopoietic necrosis virus. J Virol Methods 132:18-24

Purcell MK, Getchell RG, McClure CA, Garver KA (2011) Quantitative polymerase chain reaction (PCR) for detection of aquatic animal pathogens in a diagnostic laboratory setting. J Aquat Anim Health 23:148-161

Rose J, Schubert M (1987) Rhabdovirus genomes and their products. In: Wagner R (ed) The rhabdoviruses. Plenum, New York, NY, p 129-166

Rudakova SL, Kurath G, Bochkova EV (2007) Occurrence and genetic typing of infectious hematopoietic necrosis virus in Kamchatka, Russia. Dis Aquat Org 75:1-11

Salonius K, Simard N, Harland R, Ulmer JB (2007) The road to licensure of a DNA vaccine. Curr Opin Investig Drugs 8:635-641

Smith RD (2006) Veterinary clinical epidemiology. Taylor \& Francis, Boca Raton, FL

> Snow M, McKay P, Matejusova I (2009) Development of a widely applicable positive control strategy to support detection of infectious salmon anaemia virus (ISAV) using Taqman real-time PCR. J Fish Dis 32: 151-156

Sun Y, Yue Z, Liu H, Zhao Y and others (2010) Development and evaluation of a sensitive and quantitative assay for hirame rhabdovirus based on quantitative RT-PCR. J Virol Methods 169:391-396 
Troyer RM, Kurath G (2003) Molecular epidemiology of infectious hematopoietic necrosis virus reveals complex virus traffic and evolution within southern Idaho aquaculture. Dis Aquat Org 55:175-185

Troyer RM, LaPatra SE, Kurath G (2000) Genetic analyses reveal unusually high diversity of infectious haematopoietic necrosis virus in rainbow trout aquaculture. J Gen Virol 81:2823-2832

Winton JR, Einer-Jensen K (2002) Molecular diagnosis of infectious hematopoietic necrosis and viral hemorrhagic

Editorial responsibility: V. Gregory Chinchar, Jackson, Mississippi, USA septicemia. In: Cunningham CO (ed) Molecular diagnosis of salmonid diseases. Kluwer Academic, Dordrecht, p 49-79

> Winton J, Batts W, deKinkelin P, LeBerre M, Bremont M, Fijan $N$ (2010) Current lineages of the epithelioma papulosum cyprini (EPC) cell line are contaminated with fathead minnow, Pimephales promelas, cells. J Fish Dis 33:701-704

Wolf K (1988) Infectious hematopoietic necrosis virus. In: Wolf $\mathrm{K}$ (ed) Fish viruses and fish viral diseases. Cornell University Press, Ithaca, NY, p 83-114

Submitted: April 17, 2013; Accepted: July 1, 2013

Proofs received from author(s): September 28, 2013 